\title{
Review Article \\ The Role of Innate Immunity in Pulmonary Infections
}

\author{
Huihui Zhang $\mathbb{D}^{1}{ }^{1}$ Fang He $\mathbb{D},{ }^{1}$ Pan Li, ${ }^{1}$ Philip R. Hardwidge, ${ }^{2}$ Nengzhang Li, ${ }^{1}$ \\ and Yuanyi Peng $\mathbb{B D}^{1}$ \\ ${ }^{1}$ College of Animal Medicine, Southwest University, Chongqing, China \\ ${ }^{2}$ College of Veterinary Medicine, Kansas State University, Manhattan, KS, USA
}

Correspondence should be addressed to Yuanyi Peng; pyy2002@sina.com

Received 31 October 2020; Revised 26 December 2020; Accepted 8 January 2021; Published 23 January 2021

Academic Editor: Paul Ashwood

Copyright ( 92021 Huihui Zhang et al. This is an open access article distributed under the Creative Commons Attribution License, which permits unrestricted use, distribution, and reproduction in any medium, provided the original work is properly cited.

\begin{abstract}
Innate immunity forms a protective line of defense in the early stages of pulmonary infection. The primary cellular players of the innate immunity against respiratory infections are alveolar macrophages (AMs), dendritic cells (DCs), neutrophils, natural killer (NK) cells, and innate lymphoid cells (ILCs). They recognize conserved structures of microorganisms through membranebound and intracellular receptors to initiate appropriate responses. In this review, we focus on the prominent roles of innate immune cells and summarize transmembrane and cytosolic pattern recognition receptor (PRR) signaling recognition mechanisms during pulmonary microbial infections. Understanding the mechanisms of PRR signal recognition during pulmonary pathogen infections will help us to understand pulmonary immunopathology and lay a foundation for the development of effective therapies to treat and/or prevent pulmonary infections.
\end{abstract}

\section{Introduction}

Lung tissue is continuously exposed to various pathogenic microorganisms in the environment, leading to lung infections or lung diseases. The innate immune system is the first line of defense against pathogens and includes a range of immune cells and related mechanisms that nonspecifically recognize and resist infections [1-4]. The main pathogens of lung infection include Streptococcus pneumoniae, Staphylococcus aureus, Legionella pneumophila, Chlamydia pneumoniae, Klebsiella pneumoniae, and Pseudomonas aeruginosa [4-7]. The rapid identification of nonselfexogenous pathogens and their effective elimination with a complex set of defense mechanisms is a testament to the efficiency of the innate immune cells within the airways and lungs. Innate immune cells include alveolar macrophages (AMs), neutrophils, dendritic cells (DCs), natural killer cells (NK), and large mononuclear cells, which can recognize pathogen-associated molecular patterns (PAMPs) such as components of bacteria via their pattern-recognition receptors (PRRs) $[8,9]$.
Successful pathogenic identification and appropriate responses are essential for effective pulmonary host defense [10]. One of the primary mechanisms for bacterial growth containment at the site of infection and consequently for minimizing bacterial dissemination is the PRR-mediated innate immune responses. PRRs, such as Toll-like receptor (TLRs), Nod-like receptors (NLRs) [11], and retinoic acid inducible gene I- (RIG-I-) like receptors (RLRs) [12], are involved in innate immune responses and/or apoptosis [13]. Therefore, PRR-mediated signaling pathways play a significant role in the synergistic inflammatory responses and the balance of tissue homeostasis.

TLRs are important for the pathogen recognition and host immune response initiation. Human and mice contain 10 (TLR1-10) and 12 (TLR1-9, 11-13) TLRs, respectively [14]. TLR1, TLR2, TLR4, TLR5, TLR6, and probably TLR12 of mice and TLR10 of humans are located on the cell surface $[14,15]$. TLR3, TLR7, TLR8, and TLR9 localize in intracellular vesicles such as endoplasmic reticulum (ER), endosome, lysosome, and endolysosome [14, 15]. Recent studies have shown that TLR11 is expressed both extracellularly and 
intracellularly in human cells $[15,16]$. TLR13 is also expressed in intracellular vesicles [15]. Plasma membranebound TLRs (TLR2/1, TLR2/6, TLR4, and TLR5) and endosome membrane-bound TLRs (TLR2/1, and TLR9) are mainly involved in the recognition of lung bacteria $[17,18]$, while TLR3, TLR7, and TLR8 recognize nucleic acids of viruses during pulmonary infections [19].

NLRs are expressed in the nucleus and cytoplasm [20]. There are more than 20 receptors in the NLR family, which have three domains: the N-terminal effector domain, the central NOD domain, and the leucine-rich repeat C-terminal domain [20]. N-terminal functional domains are divided into four groups: transactivator activation domain, baculovirus inhibitor of apoptosis (BIR), caspase recruitment domain (CARD), and pyrin domain (PYD) $[12,21]$. NLRPs (nucleotide-binding oligomerization domain-like receptors proteins) are key molecules in the innate immune response to pulmonary infection. The NLRP of NLRs are made up of 14 proteins, of which NLRP1, NLRP3, NLRP6, NLRP7, and NLRP12 form inflammasomes, consisting of NLRP, ASC, and procaspase-1 $[11,20]$. Inflammasomes formed by these NLRs regulate cytokine IL-1 family and pyrolytic cell death, nuclear factor kappa-light-chain-enhancer of activated B cell- (NF- $\kappa \mathrm{B}-$ ) dependent inflammatory mediators, autophagy, or reactive oxygen species (ROS) production $[11,20]$. In addition, unlike other NLR members, the N-terminus of NLRCs contain a special CARD (apoptosis-associated speck-like protein (ASC)), which is also known as the death domain (DD) folding zone [22]. Different NLRs can detect different lung pathogens. Several inflammasomes are activated as part of the host innate immune response during different bacterial infections.

This review discusses recent advances on the function of innate immune cells in lung bacterial infections, and highlights the mechanisms used by pathogens to modulate or interfere with PRR relevant signaling in the pulmonary antibacterial responses for bacterial pathogens.

\section{Innate Immune Cells in Pulmonary Infections}

2.1. Alveolar Macrophages in Pulmonary Infections. There are three types of permanent tissue macrophages in the lung, including AMs, interstitial macrophages, and bronchial macrophages [23]. These cells mediate opsonophagocytosis and nonopsonophagocytosis of inhaled or exhaled pathogens [24]. AMs play a central role in maintaining environmental stability and inducing effective defense mechanisms [25]. Pathogens such as L. pneumophila, Actinobacillus pleuropneumoniae, and Mycobacterium tuberculosis invade the lung and activate AMs to produce proinflammatory cytokines and chemokines, such as interleukin- $1 \alpha / \beta$ (IL- $1 \alpha / \beta)$, IL- 6 , tumor necrosis factor- $\alpha$ (TNF- $\alpha$ ), interferon- $\alpha / \beta$ (IFN- $\alpha / \beta)$, and CXC chemokine ligand (CXCL2) [26-33]. Under the pathological conditions of inflammation, injury, and infection, the subgroup of AMs is different in the lung, namely, tissueresident AMs (TR-AMs) and monocyte-derived AMs (MoAMs) $[34,35]$. Since mice infected with viruses consume a large amount of TR-AMs and are accompanied by a large number of circulating blood mononuclear cells into the lungs, Mo-AMs become increasingly indistinguishable from TR-AMs as the lung returns to homeostasis [36, 37]. It is not well understood whether the functions of macrophages with different origins and locations are the same or whether they have the ability to transform. Each macrophage lineage arrives in the lung at a different time, destined to become a specific type of macrophage with a unique microanatomical niche and renewal mechanism [38]. Recent studies have presented compelling evidence that Mo-AM apolipoprotein E is beneficial to the resolution of lung fibrosis, supporting the notion that Mo-AMs may have distinct functions in different phases of lung fibrogenesis [39]. Therefore, exploring the number and function of colonized AMs and AMs differentiated by circulating blood monocytes, lung mesenchymal macrophages, and their relationship with each other is of significance for studying inflammatory mechanisms caused by pathogenic bacteria.

2.2. Neutrophils in Pulmonary Infections. Neutrophils are involved in the removal of exogenous and endogenous cellular debris and play an essential role in the pathogenesis of many respiratory infections. Acute lung inflammation, triggered by neutrophils, can be viewed as pathogenic, because their activation promotes further damage in the early phases of the inflammatory response [40]. Once specific receptors (such as a toll-like receptor) recognize antigen, releasing a cascade of mediators and leading to a chemotactic signal, neutrophils are recruited into the lung interstitium followed by a transepithelial migration into the alveolar space [41, 42]. For example, $P$. aeruginosa, LPS, and $\beta$-glucans promote the recruitment of circulating neutrophils, in which proinflammatory cytokine production (TNF- $\alpha$, IFN- $\gamma$, and IL-8) and inflammatory chemokines (the chemokine (C-C motif) ligand (CCL) 2 and CCL7) act synergistically to participate in lung inflammation [43-47]. These migration steps are regulated differently by the interaction of neutrophilic adhesion molecules (including CD11a, CD11b, CD44, CD162, CD29, CD54, CD47, CD31, and CD172a) [48]. These neutrophils phagocytose bacteria with the release of proteases (such as neutrophil elastase), cytotoxic molecules, and reactive oxygen species, enhancing inflammation and resulting in host damage $[47,49]$.

However, this neutrophilic infiltration also plays a role in the late phases of damaged areas for tissue regeneration [41, 42]. There are some molecular mechanisms by which neutrophils could orchestrate lung repair [50-53]. The most common mechanisms include neutrophil extracellular traps (NETs). Some of the matrix metalloproteinase (including MMP-2, 8, 9) and proresolving lipid mediators (including lipoxin A4, resolvins, and protectins) released by neutrophils directly contribute to tissue remodeling and repair [40, 50, $54,55]$. Neutrophil transmigration promotes tissue remodeling and repair by $\mathrm{Wnt} / \mathrm{B}$-catenin-dependent pathways with the release of cysteine-rich angiogenic inducer 61 (Cyr61) [56-58]. In addition, neutrophils may intercellularly transfer $m i R-223$ to epithelial cells to dampen acute lung injury through repression of poly (adenosine diphosphate-ribose) polymerase-1 (PARP-1) [59]. CXCL1 orchestrates neutrophil 
homeostasis in Klebsiella pneumoniae- and S. pneumoniaeinduced lung inflammation and sepsis $[44,60]$. Overall, these mediators stimulate apoptotic neutrophils and block neutrophil recruitment at late stages of the acute response through NETs capturing released chemokines (e.g., CCL5, CXCL12, and CXCL4) $[42,61]$.

2.3. Dendritic Cells in Pulmonary Infections. DCs, as antigenpresenting cells that connect the innate and adaptive immune systems, ensure an effective immune response during infection. Importantly, there are functional differences between the different subsets of lung DCs. Subpopulations of DC are classified into $\mathrm{CD}_{103^{+}} \mathrm{CD} 11 \mathrm{~b}^{-}$conventional DCs (cDC1), CD103- ${ }^{-} \mathrm{CD} 11 \mathrm{~b}^{+} \mathrm{cDCs}$ (cDC2), and plasmacytoid DCs (pDC) in the lungs [62-65]. cDCs, as proinflammatory initiators and mediators, shifting balance between Th1 and Th2 responses and crosstalk with neutrophils, may be two underlying mechanisms during bacterial pathogen-induced acute lung inflammation and injury [66]. Pulmonary $\mathrm{CD}_{103}{ }^{+} \mathrm{DCs}\left(\mathrm{CD}_{103}{ }^{+} \mathrm{PDCs}\right)$ is beneficial for T helper 2 cell (Th2) and Th17 immunity, while CD103 ${ }^{+} \mathrm{cDCs}$ is associated with the induction of Th1, cytotoxic T lymphocyte (CTL) responses, and regulatory $\mathrm{T}$ cells [67-70]. Following Klebsiella pneumonia infection, the detection of increased respiratory $\mathrm{CD} 03^{+}$PDC numbers enhanced antigen-specific $\mathrm{CD}^{+} \mathrm{T}$ cell responses, which may indicate possible novel PDC functions with respect to lung repair and regeneration [71]. Using transgenic mice enabling the inducible depletion of $\mathrm{CD}_{103^{+}} \mathrm{DCs}$ found that DC subset contributes to the control of mycobacterial burden, which was associated with consistently reduced levels of total and activated $\mathrm{CD} 4^{+}$and $\mathrm{CD} 8^{+}$ T cells and Th1-related cytokines (IFN- $\gamma$ and TNF- $\alpha$ ) [72]. Pasteurella multocida triggers the maturation of DCs and IL-12 production, a cytokine known to induce differentiation of native $\mathrm{T}$ cells into interferon- $\boldsymbol{\gamma}$ - (IFN- $\boldsymbol{\gamma}$-) producing Th1 cells, which are resistant to infection $[73,74]$. These findings suggest that bacteria target the high plasticity of $\mathrm{T}$ cell subtypes to enhance their pathogenicity and may gain advantages in survival and reproduction. Clearly, more work is required to address (i) the mechanism of DCs in manipulating native $\mathrm{T}$ cell differentiation and (ii) how to prolong neutrophil survival during bacterial pathogen infection.

2.4. Natural Killer Cells in Pulmonary Infections. NK cells constitute the first line of defense against pathogenic microorganisms. There is increasing evidence that under steady-state conditions, the frequency of NK cells in the total lymphocyte population of the lungs is high, and lung NK cells have a more mature phenotype, suggesting that quick and effective NKmediated immune responses are critical for eliminating pathogens and maintaining homeostasis in the lung [75-77]. Previous studies have indicated that IFN- $\gamma$, IL-21, and IL-22 produced by NK cells enhance the immune response through increasing IL- $1 \beta$, IL- 18 , and MIP- $1 \beta$ production and reducing IL-10 expression of monocytes in response to an intracellular pathogen in the lungs [78-82]. The mechanism by which NK cells protect against bacterial infection has not been extensively characterized but may include the production of cytokines such as tumor necrosis factor (TNF) and IFN- $\gamma$, the production of chemokines to recruit additional leukocytes, interactions with macrophages to regulate bacterial clearance, and direct bacterial killing [78, 80, 83].

Innate lymphoid cells (ILCs, e.g., NK cells, ILC1s, ILC2s, ILC3s, and lymphoid tissue-inducer cells) play important roles in the protective immunity of the pulmonary infections [84-88]. T-bet ${ }^{+}$ILC1s produce IFN- $\gamma$. GATA3 ${ }^{+}$ILC2s secrete IL-5, IL-9, and IL-13. Ror $\gamma \mathrm{t}^{+}$ILC3s produce IL-22 and IL-17 [86, 89, 90]. Upon detection of a signal from damaged epithelial cells, ILC2s release a large number of cytokines including IL-4, IL-5, IL-13, killer cell lectin-like receptor subfamily $\mathrm{G}$ member 1 (KLRG1), transforming growth factor-beta (TGF- $\beta$ ), and amphiregulin, which are also involved in lung tissue repair, immune response, and maintenance of tissue homeostasis [85, 88, 91-95]. Generally, the function of ILC2 is inhibited by ILC1 via IFN- $\gamma$ production [85]. IL-22, the cytokine produced by NK cells and ROR $\gamma$ t-expressing ILC3s, is involved in defense against rodent-adapted Klebsiella pneumoniae and Streptococcus pneumoniae $[96,97]$. Thus, although other ILCs in the lungs are rare than NK cells, ILC1s and ILC3s facilitate perplex with NK cells $[98,99]$, so previous studies on the production of cytokine IL-22 and IFN- $\gamma$ by lung NK cells may be affected by the effects of other ILCs. In addition, the role of lung ILC3 is still unclear in respiratory infection, but some of these effects have been demonstrated in maintenance of homeostasis, infection, and other mucosal barriers [100]. Therefore, further study is needed to explore the similarity and difference function of lung NK cells and other ILCs.

Recent studies provide some evidences that a prolonged alteration or enhancement in antimicrobial function of innate immune cells can itself contribute to protection from secondary infection [101]. This functional reprogramming of innate immune cells such as myeloid and NK cells, termed trained immunity [102]. From this point of view, we discuss the response of innate immunity to such as Bacille Calmette Guérin (BCG) and Pneumococcal Polysaccharide Vaccine (PPV). For example, Bacille Calmette Guérin (BCG) vaccine utilized an attenuated strain of Mycobacterium bovis protect chronic infection disease threats such as tuberculosis (TB) through activating NOD2 [103, 104]. Recent studies demonstrated that respiratory mucosal TB vaccination alters the airway innate immune landscape associated with airway macrophages prior to $M$. tuberculosis exposure and vaccinetrained airway macrophages enhance anti-TB innate immunity $[105,106]$. In addition, BCG revaccination of adults with latent TB infection also induces long-lived BCG-reactive NK cell responses [107]. Previous works reveal great functional plasticity of the lungs of mice in defense against a bacterial pathogen through activation of innate immunity protects [108]. PPV is effective in preventing invasive pneumococcal infections in immunocompetent patients with indications for receiving the vaccine [109, 110]. Additionally, macrophage-mediated innate immunity activated through Pneumococcal conjugate vaccination (PCV) treatment intracellular killing of secondary S. pneumoniae [111]. It is important to investigate enhancement of the pulmonary innate antimicrobial defenses especially in the complex context of sequential infection or coinfection. 


\section{Innate Immune Recognition Mechanisms in Pulmonary Infections}

Bacteria binds cell receptors, such as intercellular adhesion molecule 1 (ICAM-1), sialic acid, platelet activating factor (PAF), and glycine 6-phosphate receptor to recognize PRRs downstream signaling [112]. In this part, we will summarize the current knowledge of the multiple roles of TLRs in lung bacterial infections and highlight the mechanisms by which pathogens regulate or interfere with TLR signaling in the lungs. In order to clarify the complex NLR signaling network, we reviewed the roles of 7 different NLR family members (NOD1, NOD2, NLRC4, NLRC5, NLRP1, NLRP3, NLRP6, NLRP7, and NLRP12) involved in lung infections.

\subsection{Toll-Like Receptors in Pulmonary Infections}

\subsubsection{Plasma Membrane-Bound TLRs}

(1) TLR2-TLR1/TLR6. TLR2 recognizes a variety of PAMPs, including lipoproteins, lipopeptides, $\beta$-glucans, glycoproteins, and zymosans, thereby recruiting TIR domaincontaining adaptor protein (e.g., myeloid differentiation factor 88 (MyD88), Toll-IL-1R domain-containing adapter protein (TIRAP), TIR domain-containing adapter inducing IFN- $\beta$ (TRIF), or TRIF-related adapter molecule (TRAM)) $[14,113]$. TLR2 signaling is essential for bacterial clearance and survival in the lung of mice infected with S. pneumoniae, P. Aeruginosa, L. pneumophila, Brucella melitensis, Acinetobacter baumannii, Mycoplasma, M. tuberculosis, and S. aureus, indicating the importance of the TLR2 pathway for protecting the host $[13,114-124]$ (Figure 1). In most cases, TLR2 forms heterodimers with TLR1 and/or TLR6 [122]. After bacterial recognition, heterodimers of TLR1-TLR2 and TLR2-TLR6 on the surface of macrophages and cDCs activate NF- $\kappa$ B through the recruitment of TIRAP and MyD88 to induce the expression of inflammatory cytokines [125]. Synthetic bacterial lipopeptides are recognized from within endosomes by TLR2/1 $[126,127]$. TLR2/1 is activated within the endosome and induces type I IFN via unique MyD88-dependent activation of IFN-regulatory factor 3 (IRF3) and IRF7 [127-129] (Figure 1).

(2) TLR4. Plasma membrane-bound TLR4 recognizes a variety of gram-negative bacterial LPS, including B.melitensis, $P$. aeruginosa, A. baumannii, S. pneumoniae, E. coli, K. pneumoniae, and Haemophilus influenzae [130-133]. LPS binds to CD14 (Cluster of Differentiation), thereby promoting the transfer of LPS to the TLR4/MD-2 complex, activating p38, extracellular signal-regulated kinases (ERK), and c-Jun Nterminal kinases (JNKs). Macrophages and primordial human alveolar type II (ATII) cells release large amounts of TNF- $\alpha$, IL-8, and monocyte chemoattractant protein 1 (MCP-1) [134]. M. pneumoniae activates mitogen-activated protein kinases (MAPKs) by recognizing TLR2 and TLR4 and activates NF- $\kappa \mathrm{B}$ via MyD88 to produce inflammatory factors such as pro-IL-1 $\beta$ [135]. After bacterial recognition, TLR4 initially recruits TIRAP and MyD88 and then activates NF- $\kappa$ B and p38 MAPK via interleukin-1 receptor-associated kinases (IRAKs), TNF receptor-associated factor 6 (TRAF6), and TGF beta-activated kinase 1 (TAK1) complexes [122, 136-141] (Figure 1). Furthermore, TLR4 is endocytosed to the Rab1la-positive phagosome to form a complex with TRAM and TRIF, which then activates the TRAF3-TANKbinding kinase 1 (TBK1)-IRF3 axis to induce expression of type I IFN [142, 143] (Figure 1).

(3) TLR5. TLR5 is expressed on the cell surface and recognizes bacterial flagella [143]. Numerous studies have investigated the importance of MyD88-dependent TLR5 in pathogen phagocytosis and neutrophil/AMs/DCs clearance in the lung [144-148]. The antibacterial effect of intranasal flagellin in mouse model of pneumococcus respiratory infection indicates that flagellin has potential value as a therapeutic agent for the control of pulmonary infection [149]. In rodents, TLR5 is critical for mucosal intrinsic defense activity of Salmonella enterica, $P$. aeruginosa, S. pneumoniae, and uropathogenic E. coli $[150,151]$. After bacterial recognition, plasma membrane-bound TLR5 recruits MyD88, followed by activation of NF- $\kappa$ B through IRAKs, TRAF6, TAK1, and $\mathrm{I} \kappa \mathrm{B}$ kinase (IKK) complexes to induce expression of inflammatory cytokines and chemokine gene, such as IL-8, IL-6, TNF- $\alpha$, CXCL1, CXCL2, and CCL20 [152-155] (Figure 1).

\subsubsection{Endosome Membrane-Bound TLRs}

(1) TLR9. Endosome membrane-bound TLR9 plays an important role in activating innate immunity by recognizing CpG-specific motifs found in microbial DNA [14]. For example, deficient in either TLR9 or MyD88 was impaired in bacteria uptake and clearing the airway infection caused by $S$. pneumoniae [156]. Mice lacking TLR9 are unable to produce Th1 effector cells, resulting in increased bacterial load in the lungs [130]. Thus, TLR9 plays a detrimental role in $P$. aeruginosa pneumonia and methicillin-resistant $S$. aureus pneumonia [157]. Additionally, a study indicated that $P$. aeruginosa DNA reduced IL- $1 \beta$ and NO production by TLR9 signaling, impairing the ability of activated AMs to clear bacteria [158]. Finally, after bacterial recognition, TLR9 activates MyD88-TRAF6-dependent NF- $\kappa$ B to induce production of IFN and inflammatory cytokines/chemokines [15] (Figure 1).

\subsection{NOD-Like Receptors and Inflammasomes in Pulmonary Infections}

3.2.1. NOD1 and NOD2. CARD mainly includes NOD1 and NOD2. Although NOD1 and NOD2 are similar in structure, their activated ligands have different roles in lung immunity. For example, compared with NOD2, NOD1 does not play an important role in immune response to A. baumannii infection $[159,160]$. NOD1 recognizes C. pneumoniae, L. pneumophila, K. pneumoniae, $H$. influenzae, and $P$. aeruginosa [159, 161-163]. NOD2 plays an important role in host against viral and bacterial pathogens of the lung, such as $S$. pneumoniae, S. aureus, E. coli, C. pneumoniae, M. tuberculosis, and A. baumannii $[159,164]$.

Previous studies characterizing NOD1 and NOD2 members of the NLR family have shown that these NLR have 


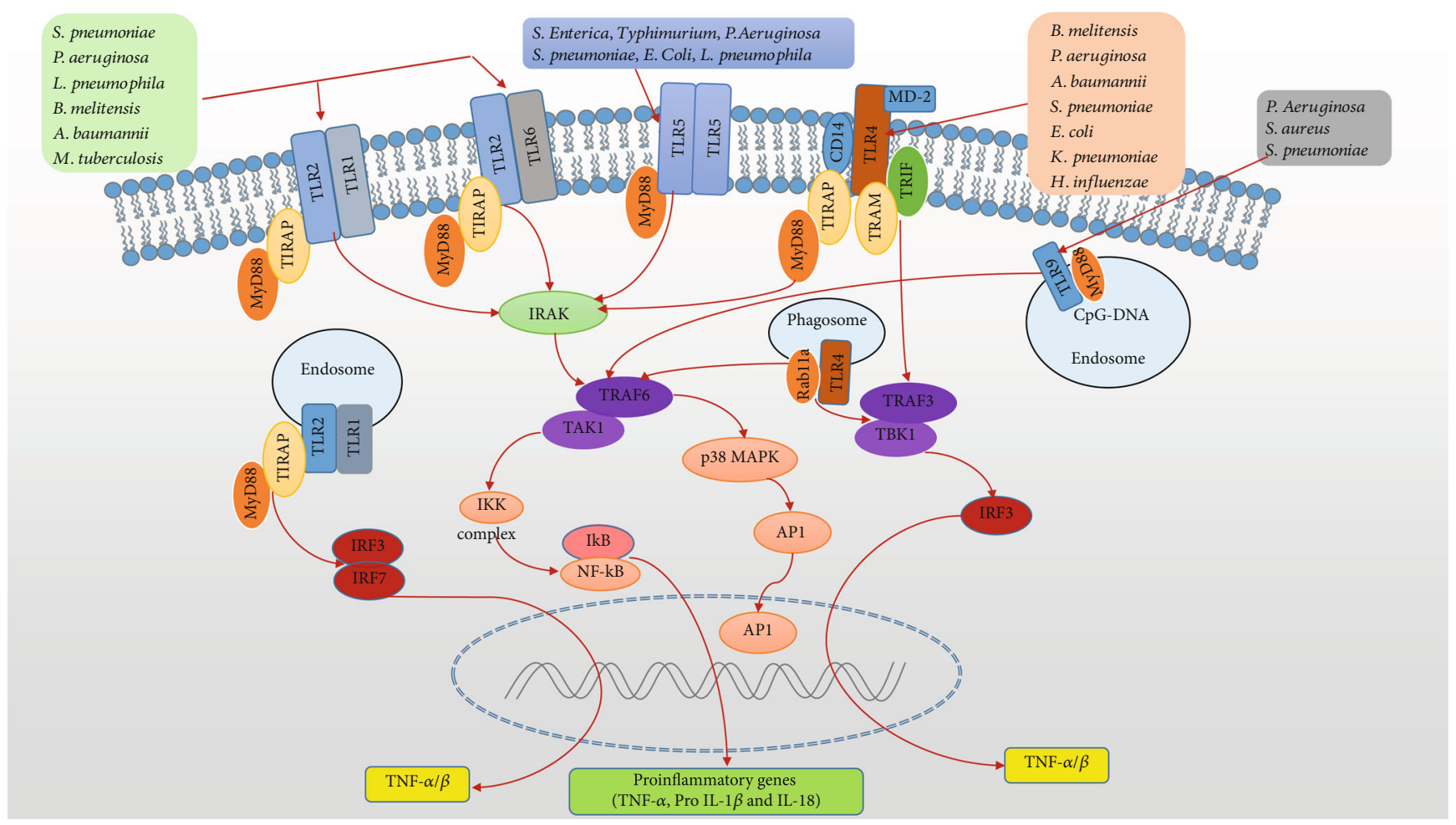

FIGURE 1: Overview of the Toll-like receptor-signaling pathway during pulmonary infections. Plasma membrane-bound TLRs (TLR1, 2, 4, 5, 6) and endosome membrane-bound TLRs (TLR9) recognize bacteria in the lungs. After bacterial recognition, TLR2 with TLR1 or TLR6 and TLR4 (in association with MD-2 and CD14) recruit TIRAP and MyD88, whereas TLR5 and TLR9 recruit MyD88. TLRs activate IRAK, followed by recruitment of TRAF6, eventually leading to activation of NF- $\kappa \mathrm{B}$ and MAPKs to the nucleus and the expression of inflammatory cytokines. However, in inflammatory monocytes infected with viruses, TLR2 is activated within the endosome, followed by induction of type I IFN via unique MyD88-dependent activation of IRF3 and IRF7. In addition, TLR4 also recruits the adaptor TRIF and activates TRAF3-TBK1-IRF3 axis to produce type I IFN. TLR: Toll-like receptor; MyD88: myeloid differential protein-88; TIRAP: Toll-IL1R domain-containing adapter protein; IRAK: IL-1 receptor-associated kinase; TRAF6: tumor necrosis factor receptor-associated factor 6; NF- $\kappa$ B: nuclear factor $-\kappa B$; MAPKs : mitogen-activated protein kinases; TRIF: TIR domain-containing adapter inducing IFN- $\beta$; IRF: IFN regulatory factor; TRAM: TRIF-related adapter molecule; ssRNA: single-stranded RNA; dsRNA: double-stranded RNA; A. baumannii: Acinetobacter baumannii; E. coli: Escherichia coli; K. pneumoniae: Klebsiella pneumoniae; L. pneumophila: Legionella pneumophila; H. influenzae: Haemophilus influenzae; M. tuberculosis: Mycobacterium tuberculosis; P. aeruginosa: Pseudomonas aeruginosa; S. pneumoniae: Streptococcus pneumoniae; B. melitensis: Brucella melitensis; S. enterica: Salmonella enterica.

protective effects against microbial pathogens, and the lack of these NLR has led to increased morbidity and mortality in infected animals [165]. NOD1 and NOD2 in macrophages infected by $M$. pneumoniae coordinate host immune defenses by producing IFN- $\gamma$, nitrogen oxides, IL-12p40, and macrophage inflammatory protein-2 [135]. NOD1 and NOD2 activate NF- $\kappa \mathrm{B}$ and MAPK through the serinethreonine kinase RIP2, resulting in the production of proinflammatory cytokines, chemokines, and adhesion molecules (Figure 2).

\subsubsection{Inflammasomes}

(1) NLRP3. The best characterized inflammasome is NLRP3, which is primarily up-regulated in immune and inflammatory cells after infection of multiple pathogens, such as $K$. pneumoniae, S. pneumoniae, S. aureus, C. pneumoniae, $C$. neoformans, M. tuberculosis, L. pneumophila, Francisella tularensis, Moraxella catarrhalis, Listeria monocytogenes, and Paracoccidioides brasiliensis, A. fumigatus, and A. bau- mannii $[20,158,166-169]$. The formation of the inflammasome leads to caspase- 1 activation that triggers pyroptosis and activation of interleukin- $1 \beta$ (IL- $1 \beta)$ and IL-18 that eventually contributes to bacterial clearance $[170,171]$ (Figure 2). In recent years, the important protective role of the NLRP3 inflammasome is indicated by enhanced bacterial growth in the lungs of NLRP3 knockout (KO) and Asc knockout (KO) mice infected with serotype 2 S. pneumoniae (D39) [169]. Importantly, infected NLRP3 deficient (Nlrp3 ${ }^{-1-}$ ) C57BL/ 6 mice failed to process and secrete IL- $1 \beta$ and displayed diminished bacterial clearance and incomplete innate immune cell activation compared to wild-type (WT) mice [172]. Those findings demonstrate that bacterial-infected mice activate NLRP3 inflammasome to produce inflammatory cytokines such as IL-1 $\beta$ [172-175]. In stark contrast to the current paradigm, infecting with lethal $S$. pneumoniae at increasing doses, results in NLRP3 inflammasome strongly impair host defense $[169,176,177]$. However, the current results are only reminded a detrimental role of ASC and NLRP3 in antibacterial defense during community-acquired 


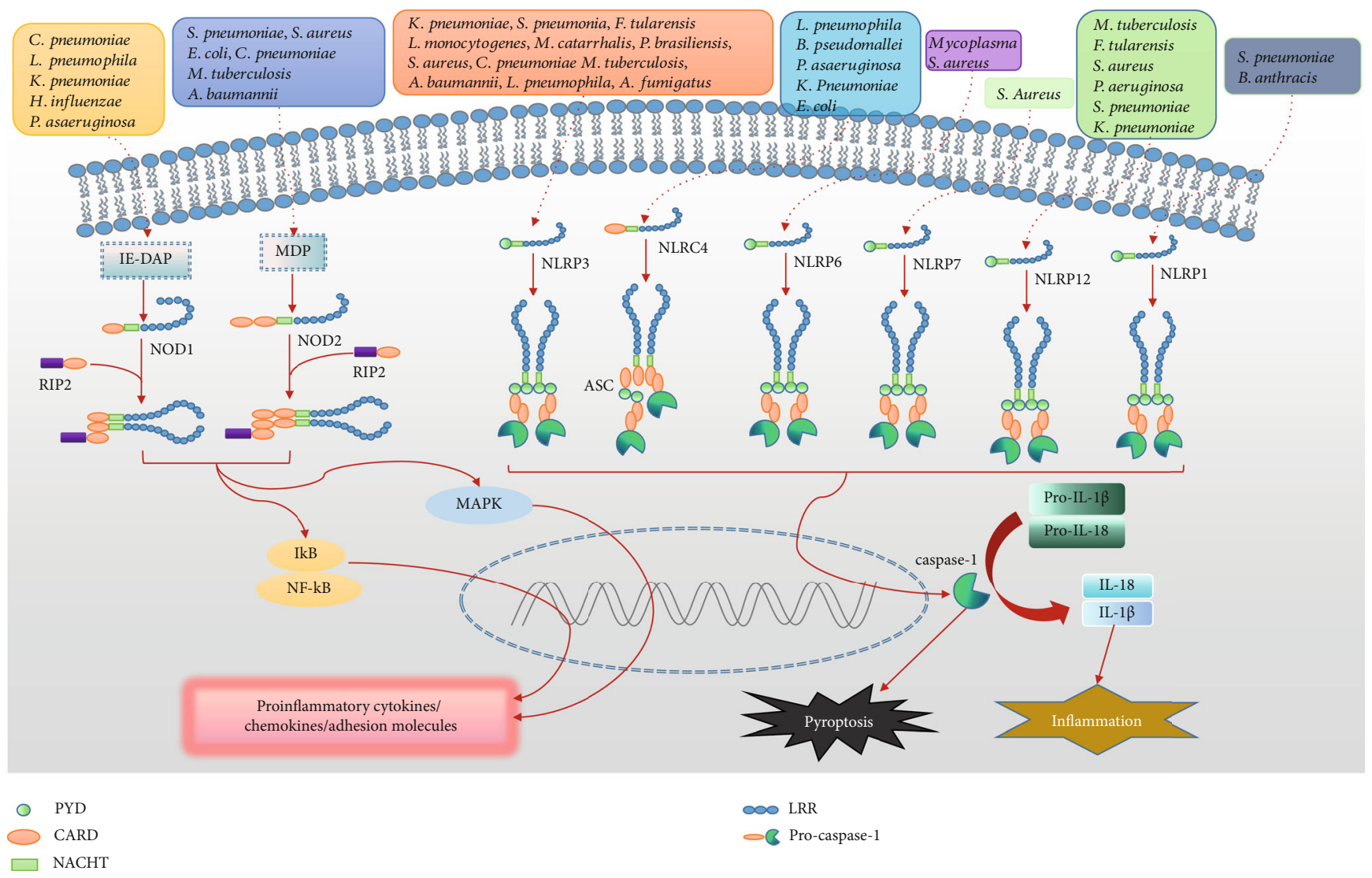

Figure 2: Overview of NLRs and RIG-I involved in pulmonary infections. Various lung pathogens are sensed by different NLRs. Cytosolic NOD1 and NOD2 recognize bacterial peptidoglycans (iE-DAP and MDP). After pulmonary pathogen activation, Nod1 and Nod2 activate downstream NF- $\kappa \mathrm{B}$ and MAPK through recruiting the serine-threonine kinase RIP2, leading to the production of proinflammatory cytokines, chemokines, and adhesion molecules. When stimulated by pulmonary bacterial pathogens, those molecules oligomerize to form the inflammasome, consisting of NLRP, ASC, and pro-caspase-1, which in turn cleaves pro-caspase 1 into its active form. Active caspase-1 can than cleaves the pro forms of IL-1 $\beta$ and IL-18 into their respective mature cytokines leading to inflammation and/or initiate pyroptosis. NOD: nucleotide-binding and oligomerization domain; NLR: nucleotide-associated oligomerization domain-like receptor; NLRP: NOD-like receptor proteins; iE-DAP: $\gamma$-D-Glu-mDAP; NLRC4: NOD-, LRR,- and CARD domain-containing-4; MD: MurNAc-LAla-D-isoGln; NF- $\kappa$ B: nuclear factor- $\kappa$ B; MAPKs: mitogen-activated protein kinases; ssRNA: single-stranded RNA; ASC: apoptosisassociated speck-like protein; CARD: caspase recruitment domain; PYD: pyrin domain; RIP2: receptor interacting protein 2; LRR: leucinerich repeat; C. pneumonia: Cryptococcus pneumoniae; B. pseudomallei: Burkholderia pseudomallei; C. neoformans: Cryptococcus neoformans; F. tularensis: Francisella tularensis; K. pneumoniae: Klebsiella pneumoniae; M. catarrhalis: Moraxella catarrhalis; P. brasiliensis: Paracoccidioides brasiliensis; Bacillus anthracis: B. anthracis.

pneumonia; it is still unclear that weather those downstream consequences of NLRP3 inflammasome activation is similar to those in the model of acute bacterial infection.

(2) NLRC4. Several lines of evidence show that NLRC4 recruits and activates caspase-1, which assembles inflammasome, leading to the pyroptosis and secretion of IL- $1 \beta$ and IL-18, thereby inhibiting L. pneumophila replication in mouse macrophages [178] (Figure 2). Additionally, NLRC4 is up-regulated in immune and inflammatory cells after infection of diverse bacteria, such as Salmonella typhimurium, K. pneumoniae, L. pneumophila, P. aeruginosa, Burkholderia pseudomallei, and E. coli [158, 179] (Figure 2). Besides, NLRC4 inhibits IL-17A-dependent neutrophil accumulation by inducing necroptosis and IL-18 activation in the lungs following $S$. aureus infections [180]. Thus, a novel therapeutic approach may be provided by modulating the function of the NLRC4 for the treatment of bacteria-induced infections in the lungs in the future.

(3) NLRP6 and NLRP12. It has been well established that NLRP6 regulates host defense inflammasome in response to bacterial infections. NLRP6 colocalizes with ASC, caspase1, and caspase-11 forming the NRLP6 inflammasome complex to induce cell pyroptosis [165]. Once activated, pro-IL- $1 \beta$ and pro-IL-18 are converted into their active and proinflammatory forms, IL- $1 \beta$ and IL-18, ready for mediating further immunological responses [181, 182] (Figure 2). In contrast to the believed proinflammatory role, as other NLRs, NLRP6 is a negative regulator of inflammatory signaling to dampen host responses against several bacterial pathogens, thereby promoting bacterial dissemination [165]. For example, compared to their WT counterparts, $\mathrm{NLRP}^{-1-}$ mice were highly resistant to infection with the pulmonary $S$. 
aureus, which were evidenced by improving survival rates and enhancing bacterial clearance in the lungs [183].

Similar to NLRP6, NLRP12 is another example of NLR family member that negatively regulates inflammatory response [184]. NLRP12 plays a protective role in Yersinia pestis infection by inducing IL-18-mediated IFN- $\gamma$ secretion [185]. NLRP $12^{-/-}$mice had reduced survival rate and enhanced bacterial burden response to pathogenic bacteria infection, such as $M$. tuberculosis, $F$. tularensis, S. aureus, $P$. aeruginosa, S. pneumoniae, and $K$. pneumoniae, suggesting that NLRP12 has functional redundancy with other NLRs or has small contribution to lung inflammation [20, 158, 184, 186] (Figure 2). In conclusion, the disadvantageous roles of NLRP6 and NLRP12 have been depicted in innate immunity of the lungs. Blocking NLRP6 and NLRP12 respectively will augment immune-associated bacterial clearance, which should be considered as a potential therapeutic intervention strategy for attenuating the tissue injury induced by pulmonary infectious diseases.

(4) Other Inflammasomes. As with other inflammasomeforming NLR family members, such as NLRP3, the formations of the NLRP1 and NLRP7 inflammasomes lead to caspase- 1 activation that trigger the pyroptosis and activation of IL- $1 \beta$ and IL-18, which eventually contribute to bacterial clearance [187-190] (Figure 2). NLRP7 responds to bacterial lipopeptides, Mycoplasma, and S. aureus infection by forming inflammasome $[20,190]$. The NOD-, LRR-, and CARD domain-containing-5 (NLRC5) inflammasome is an important regulator of major histocompatibility complex I (MHC I) expression [191]. It was reported that NLRC5 is one of the largest members of the NLR family. However, the role of NLRC5 is unclear in pulmonary immune cells and immune-related tissues of inflammatory response case [192, 193]. It should be noted that the NLRC4 inflammasome can be activated by a wide range of pathogens or hostderived factors such as lipopolysaccharide (LPS) [22]. Along the same lines, it is possible that a wide range of pathogens and/or their components or host-derived ligands can activate NLRP5. However, the function of NLRC5 is redundant with inflammasome receptors NLRP3 and NLRC4 in host defense against Salmonella [194]. NLRC5 deficiency did not affect IL$1 \beta$ production in response to various stimulations, including LPS and F. tularensis [194]. Indeed, the role of NLRC5 in pulmonary bacterial infection is extremely poor and remains to be improved. Likewise, the roles of the other members of the NLR family are still unclear in the lungs. A future goal is to explore the mechanisms of NLR and apply current understanding of NLR to reduce excessive inflammation while enhancing host defense during respiratory infections.

\section{Conclusions}

The lung contains a complex system of defense mechanisms during microbial infections. To protect the lung from microbes, the immune system forms several lines of defense. The first line of defense is established by innate immune cells (e.g., AMs, DCs, neutrophils, and NK cells). In addition, suc- cessful recognition and appropriate response of invading pathogens in the lung is essential for effective lung host defense. Recognition of cells can stimulate autophagy, phagocytosis, and clearance of necrotic cells and pathogens, further affecting local inflammatory responses. However, due to the complexity of the mechanisms, we still have a very limited perspective about the innate immune recognition of microbial pathogens and the interactions of different PRRs. Therefore, increased understanding of the PRR signaling recognition mechanisms during pulmonary pathogen infections will facilitate our knowledge of immune pathogenesis and lay the foundation for developing effective therapeutic measures.

\section{Disclosure}

The funding bodies had no role in study design, data collection or analysis, decision to publish, or preparation.

\section{Conflicts of Interest}

The authors declare that they have no conflicts of interest.

\section{Authors' Contributions}

HZ wrote a preliminary draft of this manuscript. FH, PL, PR, NL, and YP directed this work and revised the manuscript draft. All authors reviewed and approved the manuscript.

\section{Acknowledgments}

This work is supported by the Earmarked Fund for China Agriculture Research System (Beef/Yak Cattle, CARS-37), Chongqing Science \& Technology Commission (cstc2017shms-zdyfx0036 and cstc2017jcyjAX0288), and Chongqing Graduate Research and Innovation Project (CYS18075).

\section{References}

[1] H. Cheng, C. Y. Jin, J. Wu, S. Zhu, Y. J. Liu, and J. T. Chen, "Guards at the gate: physiological and pathological roles of tissue-resident innate lymphoid cells in the lung (vol 8, pg 878, 2017)," Protein \& Cell, vol. 8, no. 12, pp. 932-932, 2017.

[2] M. J. Crane, K. M. Lee, E. S. Fitz Gerald, and A. M. Jamieson, "Surviving deadly lung infections: innate host tolerance mechanisms in the pulmonary system," Frontiers in Immunology, vol. 9, 2018.

[3] G. Dong, A. L. Filho, and M. Olivier, "Modulation of hostpathogen communication by extracellular vesicles (EVs) of the protozoan parasite Leishmania," Frontiers in Cellular and Infection Microbiology, vol. 9, p. 100, 2019.

[4] Y. J. Park and H. K. Lee, "The role of skin and orogenital microbiota in protective immunity and chronic immunemediated inflammatory disease," Frontiers in Immunology, vol. 8, p. 1955, 2018.

[5] J. Maertzdorf, M. Tönnies, L. Lozza et al., "Mycobacterium tuberculosis invasion of the human lung: first contact," Frontiers in Immunology, vol. 9, p. 1346, 2018.

[6] L. A. Mandell, R. G. Wunderink, A. Anzueto et al., "Infectious Diseases Society of America/American Thoracic Society 
consensus guidelines on the management of communityacquired pneumonia in adults," Clinical Infectious Diseases, vol. 44, pp. S27-S72, 2007.

[7] S. B. Smith, M. Magid-Slav, and J. R. Brown, "Host response to respiratory bacterial pathogens as identified by integrated analysis of human gene expression data," Plos One, vol. 8, no. 9, article e75607, 2013.

[8] C. Arnold-Schrauf, M. Dudek, A. Dielmann et al., "Dendritic cells coordinate innate immunity via MyD88 signaling to control Listeria monocytogenes infection," Cell Reports, vol. 6, no. 4, pp. 698-708, 2014.

[9] C. Hang, "Guards at the gate: physiological and pathological roles of tissue-resident innate lymphoid cells in the lung," Protein \& Cell, vol. 8, no. 12, pp. 878-895, 2017.

[10] Q. Chai, Z. Yong, and L. C. Hua, "Mycobacterium tuberculosis: an adaptable pathogen associated with multiple human diseases," Frontiers in Cellular \& Infection Microbiology, vol. 8, p. 158, 2018.

[11] M. Leissinger, R. Kulkarni, R. L. Zemans, G. P. Downey, and S. Jeyaseelan, "Investigating the role of nucleotide-binding oligomerization domain-like receptors in bacterial lung infection," American Journal of Respiratory and Critical Care Medicine, vol. 189, no. 12, pp. 1461-1468, 2014.

[12] K. M. Wiese, B. M. Coates, and K. M. Ridge, "The role of nucleotide-binding oligomerization domain-like receptors in pulmonary infection," American Journal of Respiratory Cell \& Molecular Biology, vol. 57, no. 2, p. 151, 2017.

[13] B. Park, G. Park, J. Kim, S. A. Lim, and K.-M. Lee, "Innate immunity against Legionella pneumophiladuring pulmonary infections in mice," Archives of Pharmacal Research, vol. 40, no. 2, pp. 131-145, 2017.

[14] S. N. Lester and K. Li, "Toll-like receptors in antiviral innate immunity," Journal of Molecular Biology, vol. 426, no. 6, pp. 1246-1264, 2014.

[15] T. Kawai and S. Akira, "Toll-like receptors and their crosstalk with other innate receptors in infection and immunity," Immunity, vol. 34, no. 5, pp. 637-650, 2011.

[16] P. Reed, B. Alicia, C. R. Sturge, and Y. Felix, "UNC93B1 is essential for TLR11 activation and IL-12-dependent host resistance to Toxoplasma gondii," Journal of Biological Chemistry, vol. 286, no. 5, p. 3307, 2011.

[17] A. M. G. van der Aar, R. M. R. Sylva-Steenland, J. D. Bos, M. L. Kapsenberg, E. C. de Jong, and M. B. M. Teunissen, "Cutting Edge: Loss of TLR2, TLR4, and TLR5 on Langerhans cells abolishes bacterial recognition," Journal of Immunology, vol. 178, no. 4, pp. 1986-1990, 2007.

[18] C. Li, Y. Yu, W. Li et al., "Phycocyanin attenuates pulmonary fibrosis via the TLR2-MyD88-NF- $\kappa$ B signaling pathway," Scientific Reports, vol. 7, no. 1, p. 5843, 2017.

[19] P. Baral, S. Batra, R. L. Zemans, G. P. Downey, and S. Jeyaseelan, "Divergent functions of Toll-like receptors during bacterial lung infections," American Journal of Respiratory \& Critical Care Medicine, vol. 190, no. 7, pp. 722-732, 2014.

[20] C. Chaput, L. E. Sander, N. Suttorp, and B. Opitz, "NOD-like receptors in lung diseases," Frontiers in Immunology, vol. 4, no. 393, p. 393, 2013.

[21] N. Inohara, M. Chamaillard, C. McDonald, and G. Nuñez, "NOD-LRR PROTEINS: role in host-microbial interactions and inflammatory disease," Annual Review of Biochemistry, vol. 74, no. 74, pp. 355-383, 2015.
[22] Y. He, K. Xu, Y. Wang et al., "AMPK as a potential pharmacological target for alleviating LPS-induced acute lung injury partly via NLRC4 inflammasome pathway inhibition," Experimental Gerontology, vol. 125, article 110661, 2019.

[23] E. Evren, E. Ringqvist, and T. Willinger, "Origin and ontogeny of lung macrophages: from mice to humans," Immunology, vol. 160, no. 2, pp. 126-138, 2019.

[24] T. Eddens and J. K. Kolls, "Host defenses against bacterial lower respiratory tract infection," Current Opinion in Immunology, vol. 24, no. 4, pp. 424-430, 2012.

[25] J. E.-C. K. S.-M. Hong, "Alveolar macrophages treated with Bacillus subtilis spore protect mice infected with respiratory syncytial virus A2," Frontiers in Microbiology, vol. 10, p. $447,2019$.

[26] S. Bansal, V. K. Yajjala, C. Bauer, and K. Sun, "IL-1 signaling prevents alveolar macrophage depletion during influenza andStreptococcus pneumoniaeCoinfection," Journal of Immunology, vol. 200, no. 4, pp. 1425-1433, 2018.

[27] A. S. Brown, C. Yang, E. L. Hartland, and I. R. van Driel, "The regulation of acute immune responses to the bacterial lung pathogen Legionella pneumophila," Journal of Leukocyte Biology, vol. 101, no. 4, pp. 875-886, 2016.

[28] D. Kolli, M. R. Gupta, E. Sbrana et al., "Alveolar macrophages contribute to the pathogenesis of human metapneumovirus infection while protecting against respiratory syncytial virus infection," American Journal of Respiratory Cell and Molecular Biology, vol. 51, no. 4, pp. 502-515, 2014.

[29] K. M. Robinson, K. J. McHugh, S. Mandalapu et al., "Influenza A exacerbates Staphylococcus aureus pneumonia by attenuating IL- $1 \beta$ production in mice," The Journal of Immunology, vol. 191, no. 110, pp. 5153-5159, 2013.

[30] Y. Liang, J. Luo, N. Yang, S. Wang, M. Ye, and G. Pan, "Activation of the IL- $1 \beta / \mathrm{KLF} 2 / \mathrm{HSPH} 1$ pathway promotes STAT3 phosphorylation in alveolar macrophages during LPSinduced acute lung injury," Bioscience Reports, vol. 40, no. 3, 2020.

[31] H. M. Marriott, K. A. Gascoyne, R. Gowda et al., "Interleukin- $1 \beta$ regulates CXCL8 release and influences disease outcome in response to Streptococcus pneumoniae, defining intercellular cooperation between pulmonary epithelial cells and macrophages," Infection \& Immunity, vol. 80, no. 3, pp. 1140-1149, 2012.

[32] K. D. Mayer-Barber, B. B. Andrade, S. D. Oland et al., "Hostdirected therapy of tuberculosis based on interleukin-1 and type I interferon crosstalk," Nature, vol. 511, no. 7507, pp. 99-103, 2014.

[33] M. J. Mina, L. A. Brown, and K. P. Klugman, "Dynamics of increasing IFN- $\gamma$ exposure on murine $\mathrm{MH}-\mathrm{S}$ cell-line alveolar macrophage phagocytosis of Streptococcus pneumoniae," Journal of Interferon \& Cytokine Research the Official Journal of the International Society for Interferon \& Cytokine Research, vol. 35, no. 6, p. 474, 2015.

[34] A. L. Mccubbrey, L. Barthel, M. P. Mohning, E. F. Redente, and W. J. Janssen, "Deletion of c-FLIP from CD11b (hi) macrophages prevents development of bleomycin-induced lung fibrosis," American Journal of Respiratory Cell \& Molecular Biology, vol. 58, no. 1, pp. 66-78, 2017.

[35] P. A. Reyfman, J. M. Walter, N. Joshi et al., "Single-cell transcriptomic analysis of human lung provides insights into the pathobiology of pulmonary fibrosis," American Journal of Respiratory and Critical Care Medicine, vol. 199, no. 12, pp. 1517-1536, 2018. 
[36] N. Joshi, J. M. Walter, and A. V. Misharin, “Alveolar macrophages," Cellular Immunology, vol. 330, pp. 86-90, 2018.

[37] N. V. Rooijen and E. Hendrikx, "Liposomes for specific depletion of macrophages from organs and tissues," Methods in Molecular Biology, vol. 605, pp. 189-203, 2010.

[38] S. Y. S. Tan and M. A. Krasnow, "Developmental origin of lung macrophage diversity," Development, vol. 143, no. 8, pp. 1318-1327, 2016.

[39] H. Cui, D. Jiang, S. Banerjee et al., "Monocyte-derived alveolar macrophage apolipoprotein E participates in pulmonary fibrosis resolution," JCI Insight, vol. 5, no. 5, 2020.

[40] J. Blázquez-Prieto, I. López-Alonso, C. Huidobro, and G. M Albaiceta, "The emerging role of neutrophils in repair after acute lung injury," American Journal of Respiratory Cell \& Molecular Biology, vol. 59, no. 3, pp. 289-294, 2018.

[41] S. J. Forbes and N. Rosenthal, "Preparing the ground for tissue regeneration: from mechanism to therapy," Nature Medicine, vol. 20, no. 8, pp. 857-869, 2014.

[42] J. Wang, M. Hossain, A. Thanabalasuriar, M. Gunzer, C. Meininger, and P. Kubes, "Visualizing the function and fate of neutrophils in sterile injury and repair," Science, vol. 358, no. 6359, pp. 111-116, 2017.

[43] J. Liu, Z. Pang, G. Wang et al., "Advanced role of neutrophils in common respiratory diseases," Journal of Immunology Research, vol. 2017, no. 43, Article ID 6710278, 21 pages, 2017.

[44] S. Paudel, P. Baral, L. Ghimire et al., "CXCL1 regulates neutrophil homeostasis in pneumonia-derived sepsis caused by Streptococcus pneumoniae serotype 3," Blood, vol. 133, no. 12, pp. 1335-1345, 2019.

[45] B. Sun, X. Hu, G. Liu et al., "Phosphatase Wip 1 negatively regulates neutrophil migration and inflammation," Journal of Immunology, vol. 192, no. 3, pp. 1184-1195, 2014.

[46] I. M. Torres, Y. R. Patankar, and B. L. Berwin, "Acidosis exacerbates in vivo IL-1-dependent inflammatory responses and neutrophil recruitment during pulmonary Pseudomonas aeruginosa infection," American Journal of Physiology Lung Cellular \& Molecular Physiology, vol. 314, no. 2, p. L225, 2018.

[47] A. E. Williams, R. J. José, P. F. Mercer et al., "Original article: evidence for chemokine synergy during neutrophil migration in ARDS," Thorax, vol. 72, no. 1, 2017.

[48] F. M. Konrad, J. Wohlert, J. Gamper-Tsigaras, K.-C. Ngamsri, and J. Reutershan, "How adhesion molecule patterns change while neutrophils traffic through the lung during inflammation," Mediators of Inflammation, vol. 2019, Article ID 1208086, 16 pages, 2019.

[49] H. Domon, K. Nagai, T. Maekawa et al., "Neutrophil elastase subverts the immune response by cleaving Toll-like receptors and cytokines in pneumococcal pneumonia," Frontiers in Immunology, vol. 9, p. 732, 2018.

[50] J. Blázquez-Prieto, I. López-Alonso, L. Amado-Rodríguez et al., "Impaired lung repair during neutropenia can be reverted by matrix metalloproteinase-9," Thorax the Journal of the British Thoracic Society, vol. 73, no. 4, pp. 321-330, 2018.

[51] G. P. Fadini, L. Menegazzo, M. Rigato et al., "NETosis delays diabetic wound healing in mice and humans," Diabetes, vol. 65 , no. 4, pp. 1061-1071, 2016.

[52] C. Schauer, C. Janko, L. E. Munoz et al., "Aggregated neutrophil extracellular traps limit inflammation by degrading cytokines and chemokines," Nature Medicine, vol. 20, no. 5, pp. 515-521, 2014.
[53] S. L. Wong, M. Demers, K. Martinod et al., "Diabetes primes neutrophils to undergo NETosis, which impairs wound healing," Nature Medicine, vol. 21, no. 7, pp. 815-819, 2015.

[54] A. Aguirre, J. Blázquez-Prieto, L. Amado-Rodriguez et al., "Matrix metalloproteinase-14 triggers an anti-inflammatory proteolytic cascade in endotoxemia," Journal of Molecular Medicine, vol. 95, no. 5, pp. 487-497, 2017.

[55] A. González-López, A. Astudillo, E. García-Prieto, M. S. Fernández-García, and G. M. Albaiceta, "Inflammation and matrix remodeling during repair of ventilator-induced lung injury," American Journal of Physiology Lung Cellular \& Molecular Physiology, vol. 301, no. 4, pp. L500-L509, 2011.

[56] R. Vaidya, R. Zambrano, J. K. Hummler et al., "Recombinant CCN1 prevents hyperoxia-induced lung injury in neonatal rats," Pediatric Research, vol. 82, no. 85, pp. 863-871, 2017.

[57] S. Grazioli, S. Gil, D. An et al., "CYR61 (CCN1) overexpression induces lung injury in mice," American Journal of Physiology Lung Cellular \& Molecular Physiology, vol. 308, no. 308, p. L759, 2015.

[58] W. J. Zacharias, D. B. Frank, J. A. Zepp et al., "Regeneration of the lung alveolus by an evolutionarily conserved epithelial progenitor," Nature, vol. 555, no. 7695, pp. 251-255, 2018.

[59] V. Neudecker, K. S. Brodsky, E. T. Clambey, E. P. Schmidt, and H. K. Eltzschig, "Neutrophil transfer of mi R-223 to lung epithelial cells dampens acute lung injury in mice," Science Translational Medicine, vol. 9, no. 408, article eaah5360, 2017.

[60] L. Jin, S. Batra, D. N. Douda, N. Palaniyar, and S. Jeyaseelan, "CXCL1 contributes to host defense in polymicrobial sepsis via modulating T cell and neutrophil functions," Journal of Immunology, vol. 193, no. 7, pp. 3549-3558, 2014.

[61] A. Capucetti, F. Albano, and R. Bonecchi, "Multiple roles for chemokines in neutrophil biology," Frontiers in Immunology, vol. 11, p. 1259, 2020.

[62] T. H. Kim and H. K. Lee, "Differential roles of lung dendritic cell subsets against respiratory virus infection," Immune Network, vol. 14, no. 3, pp. 128-137, 2014.

[63] M. Guilliams, F. Ginhoux, C. Jakubzick et al., "Dendritic cells, monocytes and macrophages: a unified nomenclature based on ontogeny," Nature Reviews Immunology, vol. 14, no. 8, pp. 571-578, 2014.

[64] S. H. Naik, P. Sathe, H.-Y. Park et al., "Development of plasmacytoid and conventional dendritic cell subtypes from single precursor cells derived in vitro and in vivo," Nature Immunology, vol. 8, no. 11, pp. 1217-1226, 2007.

[65] A. Schlitzer, N. McGovern, and F. Ginhoux, "Dendritic cells and monocyte-derived cells: two complementary and integrated functional systems," Seminars in Cell \& Developmental Biology, vol. 41, pp. 9-22, 2015.

[66] L. Li, L. Dong, D. Zhao, F. Gao, and J. Yan, "Classical dendritic cells regulate acute lung inflammation and injury in mice with lipopolysaccharide-induced acute respiratory distress syndrome," International Journal of Molecular Medicine, vol. 44, no. 2, pp. 617-629, 2019.

[67] R. Lai, M. Jeyanathan, S. Afkhami et al., "CD11b+ dendritic cell-mediated anti-Mycobacterium tuberculosis Th1 activation is counterregulated by CD103+ dendritic cells via IL10," Journal of Immunology, vol. 200, no. 5, pp. 1746-1760, 2018.

[68] M. L. María, I. Salvador, C. G. Ruth, and S. David, "Batf 3dependent $\mathrm{CD} 103+$ dendritic cells are major producers of 
IL-12 that drive local Th1 immunity against Leishmania major infection in mice," European Journal of Immunology, vol. 45, no. 1, pp. 119-129, 2015.

[69] S. Shafiani, G.'s. Tucker-Heard, A. Kariyone, K. Takatsu, and K. B. Urdahl, "Pathogen-specific regulatory $\mathrm{T}$ cells delay the arrival of effector $\mathrm{T}$ cells in the lung during early tuberculosis," Journal of Experimental Medicine, vol. 207, no. 7, pp. 1409-1420, 2010.

[70] S. Shekhar and X. Yang, "Pulmonary CD103+ dendritic cells: key regulators of immunity against infection," Cellular \& Molecular Immunology, vol. 17, no. 6, pp. 670-671, 2020.

[71] H. Hackstein, S. Kranz, A. Lippitsch, A. Wachtendorf, and S. Herold, "Modulation of respiratory dendritic cells during Klebsiella pneumonia infection," Respiratory Research, vol. 14, no. 1, p. 91, 2013.

[72] V. H. Q. Koh, S. L. Ng, M. L. T. Ang, W. Lin, C. Ruedl, and S. Alonso, "Role and contribution of pulmonary $\mathrm{CD}_{103}{ }^{+}$dendritic cells in the adaptive immune response to _Mycobacterium tuberculosis_," Tuberculosis, vol. 102, pp. 34-46, 2017.

[73] S. Chakraborty, B. Kloos, N. Roetz et al., "Influence of Pasteurella multocida toxin on the differentiation of dendritic cells into osteoclasts," Immunobiology, vol. 223, no. 1, pp. 142-150, 2018.

[74] M. Yoshimatsu, H. Kitaura, Y. Fujimura, H. Kohara, Y. Morita, and N. Yoshida, "IL-12 inhibits lipopolysaccharide stimulated osteoclastogenesis in mice," Journal of Immunology Research, vol. 2015, no. 2, Article ID 214878, 8 pages, 2015.

[75] W. Jian, L. Fengqi, Z. Meijuan, S. Rui, W. Haiming, and T. Zhigang, "Lung natural killer cells in mice: phenotype and response to respiratory infection," Immunology, vol. 137, no. 1, pp. 37-47, 2012.

[76] N. Marquardt, E. Kekäläinen, P. Chen et al., "Human lung NK cells are predominantly comprised of highly differentiated hypofunctional CD69-CD56 dim cells," Journal of Allergy \& Clinical Immunology, vol. 139, no. 4, 2016.

[77] H. Sun, C. Sun, Z. Tian, and W. Xiao, "NK cells in immunotolerant organs," Cellular \& Molecular Immunology, vol. 10, no. 3, pp. 202-212, 2013.

[78] J.-E. B. Dong Oh Kim, W. S. Kim, M. J. Kim et al., “TXNIP regulates natural killer cell-mediated innate immunity by inhibiting IFN- $\gamma$ production during bacterial infection," International Journal of Molecular Sciences, vol. 21, no. 24, p. 9499, 2020.

[79] H.-C. Lai, C.-J. Chang, C.-S. Lin et al., "NK cell-derived IFN- $\gamma$ protects against nontuberculous mycobacterial lung infection," The Journal of Immunology, vol. 201, no. 5, pp. 14781490, 2018.

[80] M. Ivin, A. Dumigan, F. N. de Vasconcelos et al., "Natural killer cell-intrinsic type I IFN signaling controls Klebsiella pneumoniae growth during lung infection," Plos Pathogens, vol. 13, no. 11, article e1006696, 2017.

[81] S. Venkatasubramanian, S. Cheekatla, P. Paidipally et al., "IL21-dependent expansion of memory-like NK cells enhances protective immune responses against_Mycobacterium tuberculosis_," Mucosal Immunology, vol. 10, no. 4, pp. 1031-1042, 2017.

[82] X. Xu, I. D. Weiss, H. H. Zhang et al., "Conventional NK cells can produce IL-22 and promote host defense in Klebsiella pneumoniae pneumonia," Journal of Immunology, vol. 192, no. 4, pp. 1778-1786, 2014.
[83] A. Kupz, T. A. Scott, G. T. Belz et al., "Contribution of Thy1+ NK cells to protective IFN- $\gamma$ production during Salmonella typhimurium infections," Proceedings of the National Academy of Sciences, vol. 110, no. 6, pp. 2252-2257, 2013.

[84] K. Cavagnero and T. A. Doherty, "Cytokine and lipid mediator regulation of group 2 innate lymphoid cells (ILC2s) in human allergic airway disease," Journal of Cytokine Biology, vol. 2, no. 2, 2017.

[85] A. Głobińska and M. L. Kowalski, "Innate lymphoid cells: the role in respiratory infections and lung tissue damage," Expert Review of Clinical Immunology, vol. 13, no. 10, p. 1, 2017.

[86] S. J. Lund, A. Portillo, K. Cavagnero et al., "Leukotriene C4 potentiates IL-33-induced group 2 innate lymphoid cell activation and lung inflammation," Journal of Immunology, vol. 199, no. 3, pp. 1096-1104, 2017.

[87] B. C. Mindt, J. H. Fritz, and C. U. Duerr, "Group 2 innate lymphoid cells in pulmonary immunity and tissue homeostasis," Frontiers in Immunology, vol. 9, p. 840, 2018.

[88] C. A. Steer, I. Martinez-Gonzalez, M. Ghaedi, P. Allinger, L. Mathã, and F. Takei, "Group 2 innate lymphoid cell activation in the neonatal lung drives type 2 immunity and allergen sensitization," Journal of Allergy and Clinical Immunology, vol. 140, no. 2, pp. 593-595, 2017.

[89] M. Colonna, "Innate lymphoid cells: diversity, plasticity, and unique functions in immunity," Immunity, vol. 48, no. 6, pp. 1104-1117, 2018.

[90] J. Kim, G. Kim, and H. Min, "Pathological and therapeutic roles of innate lymphoid cells in diverse diseases," Archives of Pharmacal Research, vol. 40, no. 11, pp. 1249-1264, 2017.

[91] E. Bernasconi, C. Pattaroni, A. Koutsokera et al., "Airway microbiota determines innate cell inflammatory or tissue remodeling profiles in lung transplantation," American Review of Respiratory Disease, vol. 194, no. 10, pp. 1252-1263, 2016.

[92] L. Denney, A. J. Byrne, T. J. Shea et al., "Pulmonary epithelial cell-derived cytokine TGF- $\beta 1$ is a critical cofactor for enhanced innate lymphoid cell function," Immunity, vol. 43, no. 5, pp. 945-958, 2015.

[93] B. Griesenauer and S. Paczesny, "The ST2/IL-33 axis in immune cells during inflammatory diseases," Frontiers in Immunology, vol. 8, p. 475, 2017.

[94] C. M. Lloyd and B. J. Marsland, "Lung homeostasis: influence of age, microbes, and the immune system," Immunity, vol. 46, no. 4, pp. 549-561, 2017.

[95] M. R. Starkey, A. N. McKenzie, G. T. Belz, and P. M. Hansbro, "Pulmonary group 2 innate lymphoid cells: surprises and challenges," Society for Mucosal Immunology, vol. 12, pp. 299-311, 2019.

[96] H. Xiong, R. A. Carter, I. M. Leiner et al., "Distinct contributions of neutrophils and CCR2+ monocytes to pulmonary clearance of different Klebsiella pneumoniae strains," Infection \& Immunity, vol. 83, no. 9, pp. 3418-3427, 2015.

[97] L. Van Maele, C. Carnoy, D. Cayet et al., “Activation of type 3 innate lymphoid cells and IL-22 secretion in lung during Streptococcus pneumoniae infection," Journal of Infectious Diseases, vol. 210, no. 3, p. 493, 2014.

[98] C. Jingjing and W. Haiming, "Natural killer cells in the lungs," Frontiers in Immunology, vol. 10, p. 1416, 2019.

[99] E. Tomasello, N. Yessaad, E. Gregoire et al., "Mapping of NKp46(+) cells in healthy human lymphoid and nonlymphoid tissues," Frontiers in Immunology, vol. 3, p. 344, 2012. 
[100] A. Ardain, J. Z. Porterfield, H. N. Kløverpris, and A. Leslie, "Type 3 ILCs in lung disease," Frontiers in Immunology, vol. 10, p. 92, 2019.

[101] A. Seshadri, G. A. Brat, B. K. Yorkgitis, M. Giangola, and J. A. Lederer, "Altered monocyte and NK cell phenotypes correlate with posttrauma infection," Journal of Trauma and Acute Care Surgery, vol. 87, no. 2, pp. 337-341, 2019.

[102] P. Saz-Leal, C. Del Fresno, P. Brandi et al., "Targeting SHIP-1 in myeloid cells enhances trained immunity and boosts response to infection," Cell Reports, vol. 25, no. 5, pp. 11181126, 2018.

[103] M. N. Brooks, M. V. S. Rajaram, A. K. Azad et al., "NOD2 controls the nature of the inflammatory response and subsequent fate of Mycobacterium tuberculosis and M. bovis BCG in human macrophages," Cellular Microbiology, vol. 13, no. 3, pp. 402-418, 2011.

[104] D. M. Collins, G. W. D. Lisle, F. E. Aldwell, and B. M. Buddle, "A new attenuated_Mycobacterium bovis_vaccine protects brushtail possums (Trichosurus vulpecula) against experimental tuberculosis infection," Vaccine, vol. 25, no. 24, pp. 4659-4664, 2007.

[105] A. N. Civello, J. Spiropoulos, P. J. Sánchez-Cordón et al., “The effect of BCG vaccination on macrophage phenotype in a mouse model of intranasal _Mycobacterium bovis_ challenge," Vaccine, vol. 38, no. 30, pp. 4755-4761, 2020.

[106] M. R. D'Agostino, R. Lai, S. Afkhami, A. Khera, and Z. Xing, "Airway macrophages mediate mucosal vaccine-induced trained innate immunity against Mycobacterium tuberculosis in early stages of infection," The Journal of Immunology, vol. 205, pp. 2750-2762, 2020.

[107] B. M. N. Kagina, B. Abel, M. Bowmaker et al., "Delaying BCG vaccination from birth to 10 weeks of age may result in an enhanced memory CD4 T cell response," Vaccine, vol. 27, no. 40, pp. 5488-5495, 2009.

[108] C. G. Clement, S. E. Evans, C. M. Evans et al., "Stimulation of lung innate immunity protects against lethal pneumococcal pneumonia in mice," American Journal of Respiratory \& Critical Care Medicine, vol. 177, no. 12, p. 1322, 2008.

[109] E. D. Shapiro, A. T. Berg, R. Austrian, D. Schroeder, and J. D. Clemens, "The protective efficacy of polyvalent pneumococcal polysaccharide vaccine," New England Journal of Medicine, vol. 325, no. 21, pp. 1453-1460, 1991.

[110] C. G. Whitney, M. M. Farley, J. Hadler et al., "Active Bacterial Core Surveillance of the Emerging Infections Program Network. Decline in invasive pneumococcal disease after the introduction of protein-polysaccharide conjugate vaccine," New England Journal of Medicine, vol. 348, no. 318, pp. 1737-1746, 2003.

[111] K. Mimura, S. Kimura, C. Kajiwara et al., "Pneumococcal conjugate vaccine modulates macrophage-mediated innate immunity in pneumonia caused by Streptococcus pneumoniae following influenza," Microbes and Infection, vol. 22, no. 8, pp. 312-321, 2020.

[112] T. S. Hallstrand, T. L. Hackett, W. A. Altemeier, M. B. Gustavo, P. M. Hansbro, and D. A. Knight, "Airway epithelial regulation of pulmonary immune homeostasis and inflammation," Clinical Immunology, vol. 151, no. 1, pp. 1-15, 2014.

[113] C. Cunha, L. Romani, and A. Carvalho, "Cracking the Tolllike receptor code in fungal infections," Expert Review of Anti-infective Therapy, vol. 8, no. 10, pp. 1121-1137, 2010.
[114] M. A. Arias, L. Santiago, S. Costas-Ramon et al., "Toll-like receptors 2 and 4 cooperate in the control of the emerging pathogen Brucella microti," Frontiers in Cellular \& Infection Microbiology, vol. 6, 2017.

[115] E. T. Fuse, K. Tateda, Y. Kikuchi et al., "Role of Toll-like receptor 2 in recognition of Legionella pneumophila in a murine pneumonia model," Journal of Medical Microbiology, vol. 56, no. 3, p. 305, 2007.

[116] A. Gopalakrishnan and P. Salgame, "Toll-like receptor 2 in host defense against_Mycobacterium tuberculosis_ : to be or not to be - that is the question," Current Opinion in Immunology, vol. 42, pp. 76-82, 2016.

[117] C.-H. Kim, D.-J. Kim, S.-J. Lee et al., "Tolllike receptor 2 promotes bacterial clearance during the initial stage of pulmonary infection with Acinetobacter baumannii," Molecular Medicine Reports, vol. 9, no. 9, pp. 1410-1414, 2014.

[118] S. Knapp, C. W. Wieland, C. V. T. Veer, O. Takeuchi, and S. Akira, "Toll-like receptor 2 plays a role in the early inflammatory response to murine pneumococcal pneumonia but does not contribute to antibacterial defense," Journal of Immunology, vol. 172, no. 5, pp. 3132-3138, 2004.

[119] J. Pei, X. Ding, Y. Fan, A. Rice-Ficht, and T. A. Ficht, "Tolllike receptors are critical for clearance of Brucella and play different roles in development of adaptive immunity following aerosol challenge in mice," Frontiers in Cellular \& Infection Microbiology, vol. 2, no. 10, p. 115, 2012.

[120] F. Pène, D. Grimaldi, B. Zuber et al., "Toll-like receptor 2 deficiency increases resistance to Pseudomonas aeruginosa pneumonia in the setting of sepsis-induced immune dysfunction," Journal of Infectious Diseases, vol. 206, no. 6, pp. 932 942, 2012.

[121] M. R. M. E. Power, J. S. Marshall, T. J. Lin, and Y. Peng, "The development of early host response to Pseudomonas aeruginosa lung infection is critically dependent on MyD88 in mice," Clinical Chemistry, vol. 51, no. 10, pp. 1991-1992, 2004.

[122] S. J. Skerrett, M. H. Braff, H. D. Liggitt, and C. E. Rubens, "Toll-like receptor 2 has a prominent but nonessential role in innate immunity to Staphylococcus aureuspneumonia," Physiological Reports, vol. 5, no. 21, 2017.

[123] N. Surendran, E. M. Hiltbold, B. Heid et al., "Role of TLRs in Brucella mediated murine DC activation in vitro and clearance of pulmonary infection in vivo," Vaccine, vol. 30, no. 8, pp. 1502-1512, 2012.

[124] M. K. Yimin, S. Zhao, M. Ozaki et al., "Contribution of Tolllike receptor 2 to the innate response against Staphylococcus aureus infection in mice," Plos One, vol. 8, no. 9, article e74287, 2013.

[125] N. J. Nilsen, G. I. Vladimer, J. Stenvik et al., "A role for the adaptor proteins TRAM and TRIF in toll-like receptor 2 signaling," Journal of Biological Chemistry, vol. 290, no. 6, p. 3209, 2015.

[126] M. L. Marre, P. O. Tanja, A. S. Defrancesco, C. T. Darcy, and L. T. Hu, "Human integrin $\alpha$ (3) $\beta$ (1) regulates TLR2 recognition of lipopeptides from endosomal compartments," Plos One, vol. 5, no. 9, article e12871, 2010.

[127] D. Nicole, L. Stefan, W. Siegfried, and N. O. Gekara, "Murine toll-like receptor 2 activation induces type I interferon responses from endolysosomal compartments," Plos One, vol. 5, no. 4, article e10250, 2010. 
[128] R. Barbalat, L. Lau, R. M. Locksley, and G. M. Barton, “Tolllike receptor 2 on inflammatory monocytes induces type I interferon in response to viral but not bacterial ligands," Nature Immunology, vol. 10, no. 11, pp. 1200-1207, 2009.

[129] J. Stack, S. L. Doyle, D. J. Connolly et al., “TRAM is required for TLR2 endosomal signaling to type I IFN induction," Journal of Immunology, vol. 193, no. 12, pp. 6090-6102, 2014.

[130] J. A. Bengoechea and J. Sa Pessoa, "Klebsiella pneumoniaeinfection biology: living to counteract host defences," FEMS microbiology reviews, vol. 43, no. 2, pp. 123-144, 2018.

[131] S. Nakamura, N. Iwanaga, M. Seki et al., "Toll-like receptor 4 agonistic antibody promotes host defense against chronic Pseudomonas aeruginosa lung infection in mice," Infection \& Immunity, vol. 84, no. 7, pp. 1986-1993, 2016.

[132] L. R. Standiford, T. J. Standiford, M. J. Newstead et al., "TLR4-dependent GM-CSF protects against lung injury in Gram-negative bacterial pneumonia," American Journal of Physiology Lung Cellular \& Molecular Physiology, vol. 302, no. 5, pp. 447-454, 2012.

[133] W. U. Wei-Wei, S. P. Wang, F. Zhang, D. O. Epidemiology, and University, SM, "Role of Toll-like receptor 4 in Legionella pneumophila infection in $\mathrm{C} 3 \mathrm{H} / \mathrm{HeJ}$ mouse model," Chinese Journal of Public Health, vol. 30, no. 3, pp. 311-313, 2014.

[134] A. J. Thorley, G. Davide, L. Eric, G. Peter, Y. Alan, and T. D. Tetley, "Innate immune responses to bacterial ligands in the peripheral human lung-role of alveolar epithelial tlr expression and signalling," Plos One, vol. 6, no. 7, article e21827, 2011.

[135] K. Shima, J. Coopmeiners, S. Graspeuntner, K. Dalhoff, and J. Rupp, "Impact of micro-environmental changes on respiratory tract infections caused by intracellular bacteria," Febs Letters, vol. 590, no. 21, p. 3887, 2016.

[136] L. Brogaard, K. Klitgaard, P. M. Heegaard, M. S. Hansen, T. K. Jensen, and K. Skovgaard, "Concurrent host-pathogen gene expression in the lungs of pigs challenged with Actinobacillus pleuropneumoniae," Bmc Genomics, vol. 16, no. 1, p. $417,2015$.

[137] X. Ding, S. Jin, Y. Tong et al., "TLR4 signaling induces TLR3 up-regulation in alveolar macrophages during acute lung injury," Scientific Reports, vol. 7, no. 1, article 34278, 2017.

[138] C.-W. Hsu, S.-C. Li, N.-Y. Chang et al., "Involvement of NF$\kappa \mathrm{B}$ in regulation of Actinobacillus pleuropneumoniae exotoxin Apx I-induced proinflammatory cytokine production in porcine alveolar macrophages," Veterinary Microbiology, vol. 195, pp. 128-135, 2016.

[139] B. Li, J. Fang, Z. Zuo et al., "Activation of porcine alveolar macrophages by Actinobacillus pleuropneumoniae lipopolysaccharide via the TLR4/NF- $\kappa$ B mediated pathway," Infection \& Immunity, vol. 86, pp. IAI.00642-IAI.00617, 2017.

[140] J. L. Wang, L. Yang, K. Yang, and L. I. Huan-Rong, “Changes in transcription levels of TLR2/TLR4/CD16/CD18 of porcine pulmonary alveolar macrophages post-infected PCV2 in vivo," China Animal Husbandry \& Veterinary Medicine, vol. 40, no. 3, pp. 110-117, 2013.

[141] C. Xu, G. Chen, W. Yang et al., "Hyaluronan ameliorates LPS-induced acute lung injury in mice via Toll-like receptor (TLR) 4-dependent signaling pathways," International Immunopharmacology, vol. 28, no. 2, pp. 1050-1058, 2015.

[142] A. Skjesol, M. Yurchenko, K. Bösl et al., "The TLR4 adaptor TRAM controls the phagocytosis of Gram-negative bacteria by interacting with the Rab11-family interacting protein 2," PLOS Pathogens, vol. 15, no. 3, article e1007684, 2019.

[143] A. Vijayan, M. Rumbo, C. Carnoy, and J.-C. Sirard, "Compartmentalized antimicrobial defenses in response to flagellin," Trends in Microbiology, vol. 26, no. 5, pp. 423-435, 2018.

[144] Y. Cao, E. Zhang, J. Yang et al., "Frontline Science: nasal epithelial GM-CSF contributes to TLR5-mediated modulation of airway dendritic cells and subsequent IgA response," Journal of Leukocyte Biology, vol. 102, no. 3, p. 575, 2017.

[145] D. Descamps, M. Le Gars, V. Balloy et al., "Toll-like receptor 5 (TLR5), IL- $1 \beta$ secretion, and asparagine endopeptidase are critical factors for alveolar macrophage phagocytosis and bacterial killing," Proceedings of the National Academy of Sciences, vol. 109, no. 5, pp. 1619-1624, 2012.

[146] T. Shibata, N. Takemura, Y. Motoi et al., "PRAT4A-dependent expression of cell surface TLR5 on neutrophils, classical monocytes and dendritic cells," International Immunology, vol. 24, no. 10, pp. 613-623, 2012.

[147] I. Vicentesuarez, J. Brayer, A. Villagra, F. Cheng, and E. M. Sotomayor, "TLR5 ligation by flagellin converts tolerogenic dendritic cells into activating antigen-presenting cells that preferentially induce T-helper 1 responses," Immunology Letters, vol. 125, no. 2, pp. 114-118, 2009.

[148] H. Yamasawa, M. Bando, and Y. Sugiyama, "Impaired inflammatory responses to multiple Toll-like receptor ligands in alveolar macrophages of streptozotocin-induced diabetic mice," Inflammation Research, vol. 61, no. 5, pp. 417-426, 2012.

[149] L. Matarazzo, F. Casilag, R. Porte et al., “Therapeutic synergy between antibiotics and pulmonary Toll-like receptor 5 stimulation in antibiotic-sensitive or -resistant pneumonia," Frontiers in Immunology, vol. 10, p. 723, 2019.

[150] A. E. Morris, H. D. Liggitt, T. R. Hawn, and S. J. Skerrett, "Role of Toll-like receptor 5 in the innate immune response to acute P. aeruginosa pneumonia," American Journal of Physiology Lung Cellular \& Molecular Physiology, vol. 297, no. 6, article L1112, 2009.

[151] R. Porte, D. Fougeron, N. Muñoz-Wolf, J. Tabareau, and J.C. Sirard, "A toll-like receptor 5 agonist improves the efficacy of antibiotics in treatment of primary and influenza virusassociated pneumococcal mouse infections," Antimicrobial Agents \& Chemotherapy, vol. 59, no. 10, p. 6064, 2015.

[152] E. K. Benedikz, D. Bailey, C. N. L. Cook et al., "Bacterial flagellin promotes viral entry via an NF-kB and Toll like receptor 5 dependent pathway," Scientific Reports, vol. 9, no. 1, p. 7903, 2019.

[153] E. F. Dosunmu, R. O. Emeh, S. Dixit et al., "The antimicrobial peptide TP359 attenuates inflammation in human lung cells infected with Pseudomonas aeruginosa via TLR5 and MAPK pathways," Plos One, vol. 12, no. 5, article e0176640, 2017.

[154] P.-J. Kuo, C.-S. Rau, S.-C. Wu et al., "Metagenomic analysis of the effects of toll-like receptors on bacterial infection in the peritoneal cavity following cecum ligation and puncture in mice," Plos One, vol. 14, article e0220398, 2019.

[155] N. Munoz, L. Van Maele, J. M. Marques, A. Rial, J. C. Sirard, and J. A. Chabalgoity, "Mucosal administration of flagellin protects mice from Streptococcus pneumoniae lung infection," Infection \& Immunity, vol. 78, no. 10, pp. 4226-4233, 2010. 
[156] B. Albiger, S. Dahlberg, A. Sandgren et al., "Toll-like receptor 9 acts at an early stage in host defence against pneumococcal infection," Cellular Microbiology, vol. 9, no. 3, pp. 633-644, 2007.

[157] F. Benmohamed, M. Medina, Y. Z. Wu, S. Maschalidi, and L. Touqui, "Toll-like receptor 9 deficiency protects mice against Pseudomonas aeruginosa lung infection," Journal of Cystic Fibrosis, vol. 12, no. 3, article e90466, 2013.

[158] S. R. Kumar, S. Paudel, L. Ghimire et al., "Emerging roles of inflammasomes in acute pneumonia," American Journal of Respiratory \& Critical Care Medicine, vol. 197, no. 2, pp. 160-171, 2017.

[159] S. D. Kale, N. Dikshit, P. Kumar et al., "Nod 2 is required for the early innate immune clearance of Acinetobacter baumannii from the lungs," Scientific Reports, vol. 7, no. 1, article 17429, 2017.

[160] M.-J. Kang, J.-A. Choi, J.-H. Choi et al., "Nucleotide-binding oligomerization domain 1 is dispensable for host immune responses against pulmonary infection of Acinetobacter baumannii in mice," Laboratory Animal Research, vol. 34, no. 34, pp. 295-301, 2018.

[161] A. Alhazmi, "NOD-like receptor (s) and host immune responses with Pseudomonas aeruginosa infection," Inflammation Research, vol. 67, no. 6, pp. 479-493, 2018.

[162] F. Coulombe, S. Fiola, S. Akira, Y. Cormier, and J. Gosselin, "Muramyl dipeptide induces NOD2-dependent Ly6C high monocyte recruitment to the lungs and protects against influenza virus infection," Plos One, vol. 7, no. 5, article e36734, 2012.

[163] B. Theivanthiran, S. Batra, G. Balamayooran et al., "Retraction for Theivanthiran et al., NOD2 signaling contributes to host defense in the lungs against Escherichia coli infection," Infection \& Immunity, vol. 83, no. 5, pp. 2199-2199, 2015.

[164] B. Egarnes and J. Gosselin, "Contribution of regulatory T cells in nucleotide-binding oligomerization domain 2 response to influenza virus infection," Frontiers in Immunology, vol. 9, p. 132, 2018.

[165] P. K. Anand, R. K. S. Malireddi, J. R. Lukens et al., "NLRP6 negatively regulates innate immunity and host defence against bacterial pathogens," Nature, vol. 488, no. 7411, pp. 389-393, 2012.

[166] S. J. Cho, M. Plataki, D. Mitzel, G. Lowry, K. Rooney, and H. Stout-Delgado, "Decreased NLRP3 inflammasome expression in aged lung may contribute to increased susceptibility to secondary Streptococcus pneumoniae infection," Experimental Gerontology, vol. 105, pp. 40-46, 2017.

[167] B. M. Coates, K. L. Staricha, N. Ravindran et al., "Inhibition of the NOD-like receptor protein 3 inflammasome is protective in juvenile influenza A virus infection," Frontiers in Immunology, vol. 8, p. 782, 2017.

[168] T. Kuriakose and T.-D. Kanneganti, "Regulation and functions of NLRP3 inflammasome during influenza virus infection,” Molecular Immunology, vol. 86, pp. 56-64, 2017.

[169] M. H. P. van Lieshout, A. F. de Vos, M. C. Dessing et al., "ASC and NLRP3 impair host defense during lethal pneumonia caused by serotype Streptococcus pneumoniae in mice," European Journal of Immunology, vol. 48, no. 1, 2018.

[170] W. A. Andrade and D. S. Zamboni, "Inflammasome-dependent mechanisms involved in sensing and restriction of bacterial replication," Current Issues in Molecular Biology, vol. 25, pp. 99-132, 2018.
[171] A. Saeki, M. Sugiyama, A. Hasebe, T. Suzuki, and K. Shibata, "Activation of NLRP3 inflammasome in macrophages by mycoplasmal lipoproteins and lipopeptides," Molecular Oral Microbiology, vol. 33, no. 4, pp. 300-311, 2018.

[172] J. A. Segovia, T. H. Chang, V. T. Winter et al., "NLRP3 is a critical regulator of inflammation and innate immune cell response during Mycoplasma pneumoniae infection," Infection and Immunity, vol. 86, no. 1, article e00548-17, 2018.

[173] P. Li, Y. Shen, P. Cui et al., "Neuronal NLRC5 regulates MHC class I expression in neuro-2a cells and also during hippocampal development," Journal of Neurochemistry, vol. 152, no. 2, pp. 182-194, 2020.

[174] K. M. Robinson, K. Ramanan, M. E. Clay et al., "The inflammasome potentiates influenza/Staphylococcus aureus superinfection in mice," Jci Insight, vol. 3, no. 7, article e97470, 2018.

[175] A. E. Rodriguez, C. Bogart, C. M. Gilbert et al., "Enhanced IL$1 \beta$ production is mediated by a TLR2-MYD88-NLRP3 signaling axis during coinfection with influenza $A$ virus and Streptococcus pneumoniae," PLoS One, vol. 14, no. 2, article e0212236, 2019.

[176] R. Fang, K. Tsuchiya, I. Kawamura et al., "Critical roles of ASC inflammasomes in caspase-1 activation and host innate resistance to Streptococcus pneumoniae infection," Journal of Immunology, vol. 187, no. 9, pp. 4890-4899, 2011.

[177] E. A. McNeela, A. Burke, D. R. Neill et al., "Pneumolysin activates the NLRP3 inflammasome and promotes proinflammatory cytokines independently of TLR4," Plos Pathogens, vol. 6, no. 11, article e1001191, 2010.

[178] P. Ziltener, T. Reinheckel, and A. Oxenius, "Neutrophil and alveolar macrophage-mediated innate immune control of Legionella pneumophila lung infection via TNF and ROS," Plos Pathogens, vol. 12, no. 4, article e1005591, 2016.

[179] W. Liu, X.'n. Liu, Y. Li et al., "LRRK2 promotes the activation of NLRC4 inflammasome during Salmonella Typhimurium infection," Journal of Experimental Medicine, vol. 214, no. 10, pp. 3051-3066, 2017.

[180] S. Paudel, L. Ghimire, L. Jin, P. Baral, S. Cai, and S. Jeyaseelan, "NLRC4 suppresses IL-17A-mediated neutrophil-dependent host defense through upregulation of IL-18 and induction of necroptosis during Gram-positive pneumonia," Mucosal Immunology, vol. 12, no. 11, pp. 247-257, 2018.

[181] L. Ghimire, S. Paudel, L. L. Jin, and S. Jeyaseelan, "The NLRP6 inflammasome in health and disease," Mucosal Immunology, vol. 13, no. 3, pp. 388-398, 2020.

[182] Y. Lv, G. Ruan, Y. Liu et al., “Aberrant expression of NLRP3, NLRC4 and NLRP6 inflammasomes in patients with primary immune thrombocytopenia," Thrombosis Research, vol. 176, pp. 101-103, 2019.

[183] L. Ghimire, S. Paudel, L. Jin, P. Baral, S. Cai, and S. Jeyaseelan, "NLRP6 negatively regulates pulmonary host defense in Gram-positive bacterial infection through modulating neutrophil recruitment and function," PLoS Pathogens, vol. 14, article e1007308, 2018.

[184] L. Ghimire, S. Paudel, and S. Jeyaseelan, "NLRP12 negatively regulates pulmonary host defense in Gram-positive bacterial pneumonia," American Journal of Respiratory and Critical Care Medicine, vol. 199, 2019.

[185] G. I. Vladimer, D. Weng, S. W. Montminy Paquette et al., "The NLRP12 inflammasome recognizes Yersinia pestis," Immunity, vol. 37, no. 31, pp. 96-107, 2012. 
[186] S. Cai, S. Batra, and S. Jeyaseelan, "Nlrp 12 inflammasome recognizes Gram-negative and Gram-positive pulmonary pathogens," American Journal of Respiratory and Critical Care Medicine, vol. 187, article A4557, 2013.

[187] J. M. C. Anton, J. A. G. Romero, J. M. Cuquerella, J. V. T. Pastor, and J. V. O. Villanueva, "Alternative use of rice straw ash as natural fertilizer to reduce phosphorus pollution in protected wetland ecosystems," International Journal of Recycling of Organic Waste in Agriculture, vol. 9, no. 1, pp. 6174, 2020.

[188] M. Kovarova, P. R. Hesker, L. Jania et al., "NLRP1-dependent pyroptosis leads to acute lung injury and morbidity in mice," Journal of Immunology, vol. 189, no. 4, pp. 2006-2016, 2012.

[189] P. S. Mitchell, A. Sandstrom, and R. E. Vance, "The NLRP1 inflammasome: new mechanistic insights and unresolved mysteries," Current Opinion in Immunology, vol. 60, pp. 37-45, 2019.

[190] R. A. Ramachandran, C. Lupfer, and H. Zaki, "The inflammasome: regulation of nitric oxide and antimicrobial host defence," Nitric Oxide and Other Small Signalling Molecules, vol. 72, pp. 65-115, 2018.

[191] Y. Li, H. Li, S. Liu et al., "Pirfenidone ameliorates lipopolysaccharide-induced pulmonary inflammation and fibrosis by blocking NLRP3 inflammasome activation," Molecular Immunology, vol. 99, pp. 134-144, 2018.

[192] X. Guo, T. Liu, H. Shi et al., "Respiratory syncytial virus infection upregulates NLRC5 and major histocompatibility complex class I expression through RIG-I induction in airway epithelial cells," Journal of Virology, vol. 89, no. 15, pp. 7636-7645, 2015.

[193] P. Ranjan, N. Singh, A. Kumar et al., "NLRC5 interacts with RIG-I to induce a robust antiviral response against influenza virus infection," European Journal of Immunology, vol. 45, no. 3, pp. 758-772, 2015.

[194] H. Kumar, S. Pandey, J. Zou et al., "NLRC5 deficiency does not influence cytokine induction by virus and bacteria infections," Journal of Immunology, vol. 186, no. 2, pp. 994-1000, 2011. 